\title{
DOC-2/hDab2 Expression Is Up-Regulated in Primary Pancreatic Cancer but Reduced in Metastasis
}

\author{
Yong Huang, Helmut Friess, Jörg Kleeff, Irene Esposito, Zhaowen Zhu, Shengli Liu, \\ Samuel C. Mok, Arthur Zimmermann, and Markus W. Büchler
}

Department of Visceral and Transplantation Surgery (YH, HF, JK, IE, ZZ, SL, MWB), University of Bern, Inselspital, Bern, Switzerland; Laboratory of Gynecologic Oncology (SCM), Division of Gynecologic Oncology, Department of Obstetrics, Gynecology, and Reproductive Biology, Brigham and Women's Hospital, Harvard Medical School, Boston, Massachusetts; and Institute of Pathology (AZ), University of Bern, Switzerland

SUMMARY: DOC-2/hDab2 (DOC-2) has tumor suppressive functions in ovarian cancer and choriocarcinoma. In these tumors, it negatively influences mitogenic signal transduction of growth factors and blocks ras activity. Pancreatic cancer exhibits a high frequency of $\mathrm{K}$-ras gene mutations; however, it is not known whether $D O C-2$ expression is altered in these tumors. Therefore, we investigated DOC-2 expression in 22 pancreatic adenocarcinomas and in 6 pancreatic cancer cell lines. Findings in human tumors were compared with normal controls and correlated with clinicopathological data. Additionally, the influence of $K$-ras on DOC-2 transcription was investigated. Northern blot and Western blot analyses both demonstrated an increase of DOC-2 mRNA and protein levels in primary pancreatic cancers in comparison with normal controls. In situ hybridization showed DOC-2 mRNA expression in the majority of cancer cells of primary tumors, as well as in chronic pancreatitis-like lesions surrounding the cancer mass. Immunohistochemistry mirrored the in situ hybridization findings. In contrast, levels of expression of $D O C-2$ in lymph node metastases were markedly decreased in comparison with levels in primary tumors. In addition, in 5 metastatic pancreatic cancer cell lines, DOC-2 mRNA and protein levels were low, whereas quantitative RT-PCR demonstrated relatively higher levels in a nonmetastatic pancreatic cancer cell line. In conclusion, DOC-2 is overexpressed in primary pancreatic adenocarcinoma but down-regulated in metastatic disease, suggesting a tumor suppressor function of $D O C-2$ in the late steps of pancreatic carcinogenesis. (Lab Invest 2001, 81:863-873).

\begin{abstract}
$P$ ancreatic adenocarcinomas are the fourth or fifth 1 leading cause of cancer-related death in developed countries, with an average 5 -year survival rate of less than $0.5 \%$ (Gudjonsson, 1995). The poor prognosis of pancreatic cancer manifests itself by low resection rates, nonresponsiveness to adjuvant or palliative therapy, and a high incidence of recurrence and early metastasis formation following potentially curative resection.

It is known that various genetic and epigenetic alterations are involved in the pathogenesis of pancreatic cancer, including overexpression of mitogenic growth factors and growth factor receptors (Friess et al, 1993; Korc et al, 1992), as well as mutations of the $K$-ras proto-oncogene and p53 and Smad4 tumor suppressor genes (Friess et al, 1998). A better understanding of the underlying molecular mechanisms, including those related to metastasis in this malignancy, will hopefully contribute to improvement of early diagnosis and effective therapy in the future.
\end{abstract}

Received February 14, 2001.

This work was supported by SNF Grant 32-49494.96 from the Swiss National Science Foundation.

Address reprint requests to: Dr. Helmut Friess, Department of Visceral and Transplantation Surgery, University of Bern, Inselspital, CH-3010 Bern, Switzerland. E-mail: helmut.friess@insel.ch
DOC-2/hDab2 (DOC-2) is a candidate tumor suppressor gene that was first isolated by differential RNA display techniques (Liang and Pardee, 1992; Mok et al, 1994). In 1995, Albertsen and coworkers (Albertsen et al, 1996) reported the complete gene sequence of the 3.2-kb DOC-2 transcript and its localization at chromosome $5 \mathrm{p} 13$. It was shown that DOC-2 is the human homolog of mouse Dab2, which was cloned from a mouse macrophage library and encodes a 96-kd mitogen-responsive phosphoprotein ( $\mathrm{Xu}$ et al, 1995). The structure of DOC-2 includes a highly conserved phosphotyrosine-interacting domain at the amino terminus, suggesting its potential interaction with other proteins (Bork and Margolis, 1995; Kavanaugh and Williams, 1994). Moreover, both proteins have proline-rich domains at the carboxy terminus (Ren et al, 1993) that can bind to the SH3 motive of Grb2, thus sequestering Grb2 from the Sos/Grb2 complex (Xu et al, 1998). Because this complex is important for the activation of $K$-ras, the dissociation of Sos/Grb2 may lead to decreased activation of $K$-ras. Transfection of a full-length DOC-2 cDNA construct into ovarian cancer and choriocarcinoma cell lines significantly reduces their growth rate, both in vitro and in vivo, suggesting a potential function of DOC-2 as a tumor suppressor (Fulop et al, 1998; Mok et al, 1998). However, the importance of DOC-2 in pancreatic cancer, which exhibits a high rate of $K$-ras 
mutations (Bos, 1989), is still not known. Therefore, DOC-2 mRNA and protein expression were analyzed in primary and metastatic pancreatic cancer and cultured pancreatic cell lines. We now report that DOC-2 mRNA and protein levels are increased in primary pancreatic cancer samples but reduced in metastasized cancer cells.

\section{Results}

\section{Northern Blot Analysis in Pancreatic Tissues}

Northern blot analysis of total RNA demonstrated a 3.7-kb and 2.9-kb DOC-2 mRNA transcript (Mok et al, 1994) in normal samples and in pancreatic cancer samples without any aberrant mRNA transcripts (Fig. 1A). DOC-2 mRNA expression was present at low levels in all normal pancreatic tissue samples. In some normal pancreatic tissues, the expression levels for DOC-2 mRNA were very faint and only visible on the original autoradiographs. DOC-2 mRNA was expressed at moderate-to-high levels in 17 of 22 (77\%) pancreatic cancer samples. Densitometric analysis revealed an average 3.6-fold increase of DOC-2 mRNA levels in the pancreatic cancer samples in comparison with the normal pancreas $(p<0.001)$.

\section{Western Blot Analysis in Pancreatic Tissues}

Western blot analysis was performed in five normal and eight cancerous tissue samples, as well as in the five pancreatic cancer cell lines. Western blot analysis demonstrated a 105-kd protein band (Fulop et al, 1998) that was moderately-to-strongly present in seven of eight (88\%) cancer samples (Fig. 1B) and absent in the normal pancreatic tissue samples (Fig. 1B).

\section{In Situ Hybridization}

In situ hybridization was carried out to determine the exact site and cellular localization of DOC-2 mRNA expression in the normal and cancerous pancreas, as well as in lymph node metastases. Slides with normal ovarian tissues were used as positive controls (Fig. $2 \mathrm{~A})$, and consecutive slides hybridized with the sense probe were used to ensure specificity (Fig. 2B).

In the normal ovary, epithelium cells exhibited strong in situ hybridization signals of DOC-2 mRNA (Fig. 2A) as reported before (Fazili et al, 1999), whereas no signals were obtained when the slides were incubated with the sense probe (Fig. 2B). In pancreatic tissues, the results of the in situ hybridization were consistent with those of Northern blot analysis. In normal pancreatic tissue sections, DOC-2 mRNA expression was not present or was only faintly present in the ductal epithelium and acinar cells (Fig. 2C). However, in pancreatic cancer tissues, areas with chronic pancreatitis-like lesions adjacent to the cancer mass exhibited moderate-to-strong DOC-2 mRNA signals in the cytoplasm of degenerating acinar cells, in acinar cells dedifferentiating into pseudotubular complexes, and in papillary hyperplastic ducts. (Fig. 2D). In primary pancreatic cancer, DOC-2 mRNA expression was moderately-to-strongly present in the cytoplasm of most cancer cells (Fig. 2, E and F). However, in lymph node metastases of the same tumors, DOC-2 mRNA was only faintly present in a few cancer cells and absent in the majority of cancer cells (Fig. 2, G and $\mathrm{H})$. The remaining lymphatic tissue did not exhibit any DOC-2 mRNA expression (Fig. 2, G and H).

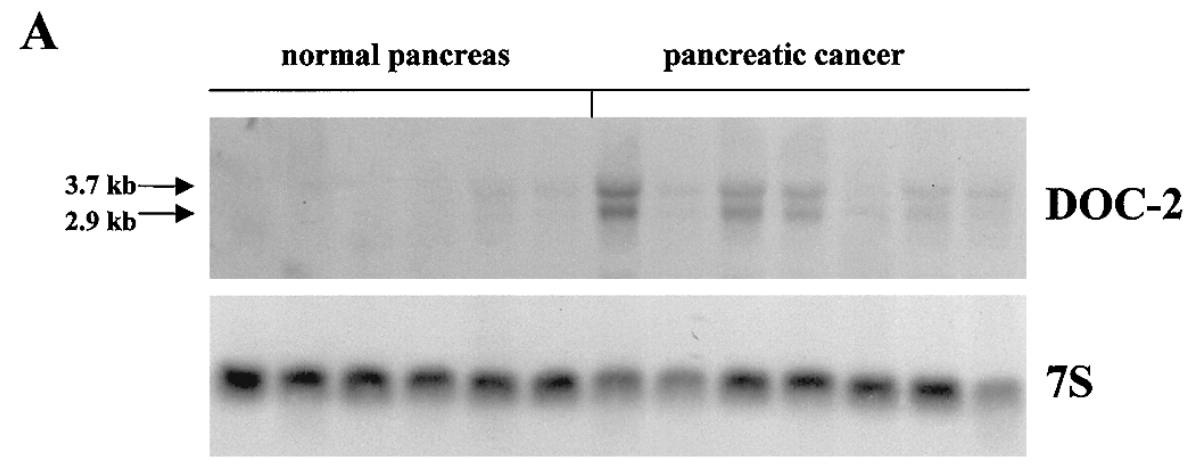

B

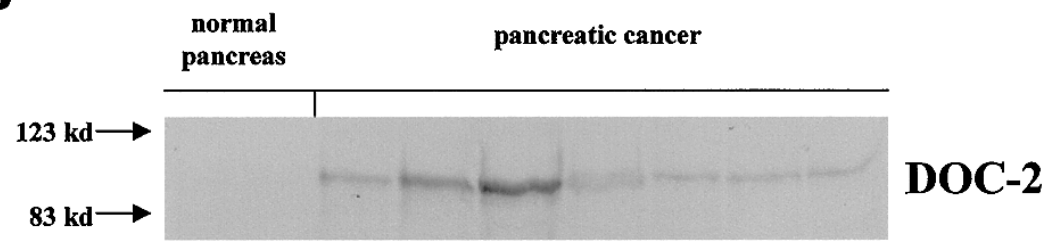

Figure 1.

Northern blot analysis of total RNA isolated from the indicated tissues and cell lines. A, Six normal pancreatic tissues and seven pancreatic cancers. The transcript sizes are indicated on the left side. B, Western blot analysis of $D O C-2$ in two normal pancreatic tissues and seven pancreatic cancers. The size markers are indicated on the left. 


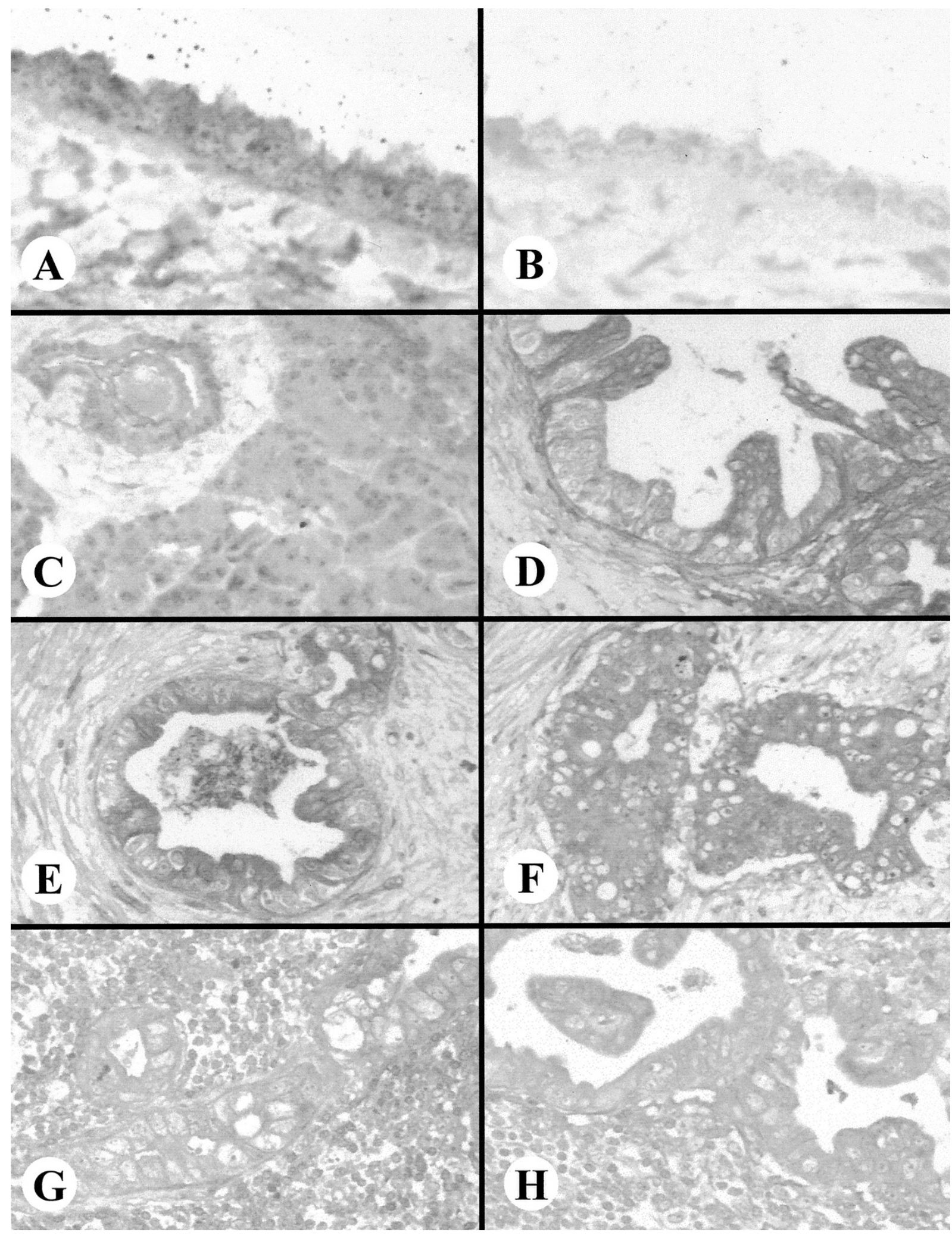

Figure 2.

In situ hybridization of DOC-2. A, Normal ovary: strong signals were present in the cytoplasm of the epithelium. B, Negative control: consecutive slides of normal ovary hybridized with the sense probe. C, Normal pancreatic tissue: normal pancreatic duct and acinar cells were faint to negative. D, Chronic pancreatitis-like lesions adjacent to the cancer mass: signals were strongly present in the hyperplastic multiple layer epithelium. E and F, Primary pancreatic cancer: the signals were moderate to strong in the cytoplasm of the cancer cells. $\mathrm{G}$ and $\mathrm{H}$, Metastatic lymph node of the same tumor: signals were weak and only present in a few cancer cells. 


\section{Immunohistochemistry}

Cellular localization of DOC-2 protein was studied by immunostaining. The immunohistochemical data matched well with the in situ hybridization findings. By immunohistochemistry, no or only faint immunoreactivity was found in ductal cells and acinar cells in the normal pancreas (Fig. 3A). In chronic pancreatitis-like lesions adjacent to the cancer mass, DOC-2 immunoreactivity was present in the cytoplasm of ductal cells of hyperplastic ducts, acinar cells dedifferentiating into pseudotubular complexes, and degenerating acinar cells (Fig. 3B). Immunoreactivity in hyperplastic multilayer epithelium was stronger than in single-layer epithelium (Fig. 3, C and D), going along with the findings of the in situ hybridization. In pancreatic cancer, cytoplasmic DOC-2 immunoreactivity was strongly present in most cancer cells (Fig. 3, E and F). Immunostaining was also performed in consecutive slides of lymph node metastases analyzed by in situ hybridization. Correspondingly, only focal and faint immunoreactivity was present in a few metastatic cancer cells, whereas the other cancer cells, as well as the remaining lymphatic tissue, were unstained (Fig. 3, $G$ and $H)$.

\section{Correlation of Northern Blot Results with Clinicopathological Parameters}

Clinicopathological parameters of the patients were correlated with DOC-2 mRNA expression values obtained by Northern blot analysis. The amount of increase over the mean in the normal controls was calculated for each cancer sample. There were no significant differences in DOC-2 mRNA expression between earlier (Stages I and II) and advanced (Stages III and IV) tumors (Fig. 4B), or in undifferentiated (Grades 3 and 4) compared with differentiated (Grades 1 and 2) tumors (Fig. 4C).

\section{DOC-2 Analysis in Cultured Pancreatic Cancer Cell Lines}

In pancreatic cancer cell lines, faint DOC-2 mRNA expression was present only in AsPC-1 cells, whereas no signals were detected in PANC-1, T3M4, MIA PaCa-2, or Capan-1 cells (Fig. 5A). There was a good correlation between DOC-2 mRNA and protein levels, except in T3M4 cells. Thus, DOC-2 protein signals were weak in AsPC-1 and T3M4 cells and absent in PANC-1, MIA PaCa-2, and Capan-1 cells (Fig. 5B).

Because it seems that the up-regulation of $D O C-2$, as well as $K$-ras mutations, occurs early in the pathogenesis of pancreatic cancer, and given the known interaction of $K$-ras and $D O C-2$, in the next sets of experiments we investigated the effects of $K$-ras on DOC-2 expression levels. To this end, we first analyzed DOC-2 expression in one cell line with $K$-ras mutation (PANC-1) and in one pancreatic cancer cell line without $K$-ras mutation $(\mathrm{BxPc}-3)$ with the highly sensitive real-time quantitative RT-PCR. This analysis revealed more than 5-fold higher DOC-2 mRNA levels in the cell line without K-ras mutation (Fig. 5C). Next, we investigated whether suppressing K-ras expres- sion would influence DOC-2 transcription in those two pancreatic cancer cell lines. To this end, a mutationmatched K-ras antisense oligonucleotide approach was performed as described previously (Kita et al, 1999). First, Western blot analysis was carried out to confirm that the K-ras antisense oligonucleotides effectively decrease $K$-ras p21 protein levels (Fig. 6A). Next, cells were treated for 24,48 , and 72 hours with the K-ras antisense oligonucleotides and the corresponding control sense oligonucleotides. As determined by real-time quantitative RT-PCR (Fig. 6B), suppressing $K$-ras expression resulted in an initial decrease and subsequent marked up-regulation of DOC-2 mRNA expression in both cell lines (Fig. 6C).

\section{Discussion}

In this study, the expression pattern of DOC-2 in the normal pancreas and pancreatic cancer was analyzed. mRNA analysis demonstrated enhanced expression in most cancer samples, which could also be confirmed on a protein level by Western blot analysis. These findings seem to contradict previous studies in ovarian cancer, where DOC-2 is decreased in cancer in comparison with normal ovarian epithelium (Mok et al, 1998). Loss of DOC-2 is believed to be an early step in malignant cell transformation in ovarian cancer (Fazili et al, 1999). DOC-2 binds to the SH3 motives of Grb2/Sos through its proline-rich domains, thus enhancing the dissociation of the Grb2/Sos complex (Xu et al, 1998), which functions as an intermediary between, for example, activated tyrosine kinase growth factor receptors and the Ras/Raf MAP kinase cascade. Because Grb2/Sos dissociation blocks growth factor-induced mitogenesis, DOC-2 was suggested to function as a tumor suppressor, an assumption that has also been supported by transfection experiments in ovarian cancer and choriocarcinoma cell lines. However, in mucinous ovarian cancer, which like pancreatic cancer has a high incidence of $K$-ras mutations (Bos, 1989; Mok et al, 1993), DOC-2 is expressed at comparable levels with respect to normal ovarian epithelium (Mok et al, 1998). These findings raise the possibility that in tumors with K-ras mutations, such as pancreatic and mucinous carcinoma, activation of cell proliferation can no longer be blocked by enhanced DOC-2 levels.

In our experiments, in situ hybridization and immunostaining revealed that $D O C-2$ mRNA and protein are not present in the ductal epithelium of normal pancreatic samples, whereas both are markedly increased in the majority of pancreatic cancer cells. Furthermore, DOC-2 mRNA and protein are present in chronic pancreatitis-like lesions adjacent to the cancer mass and are particularly strong in the hyperplastic multiple layer epithelium, in comparison with single-layer epithelium. Because chronic pancreatitis-like lesions frequently harbor K-ras mutations (Mangray and King, 1998; Rivera et al, 1997), it seems that the upregulation of DOC-2 might occur already as an early event in the pathogenesis of pancreatic cancer. This hypothesis is supported by our observation that there 


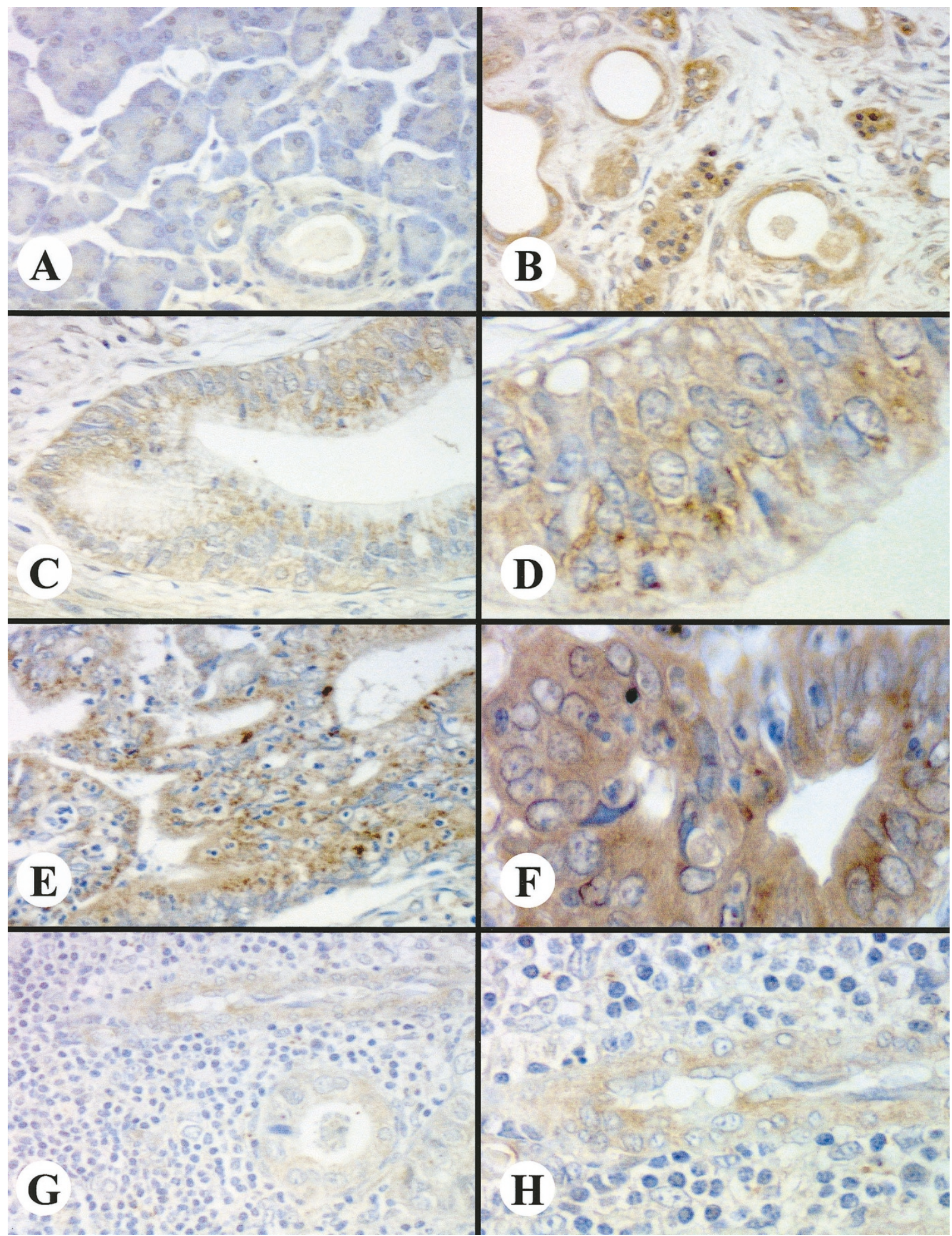

Figure 3.

Immunostaining of DOC-2. A, Normal pancreatic tissue: pancreatic ductal and acinar cells were faint to negative. B to D, Chronic pancreatitis-like lesions adjacent to the cancer mass: strong signals were found in the degenerating acinar cells and acinar cells dedifferentiating into pseudoductular complexes (B), as well as in the multiple layer epithelium. E and F, Pancreatic cancer: strong signals were present in cancer cells. G and H, Metastatic lymph nodes: only weak signals were present in a few cancer cells. 


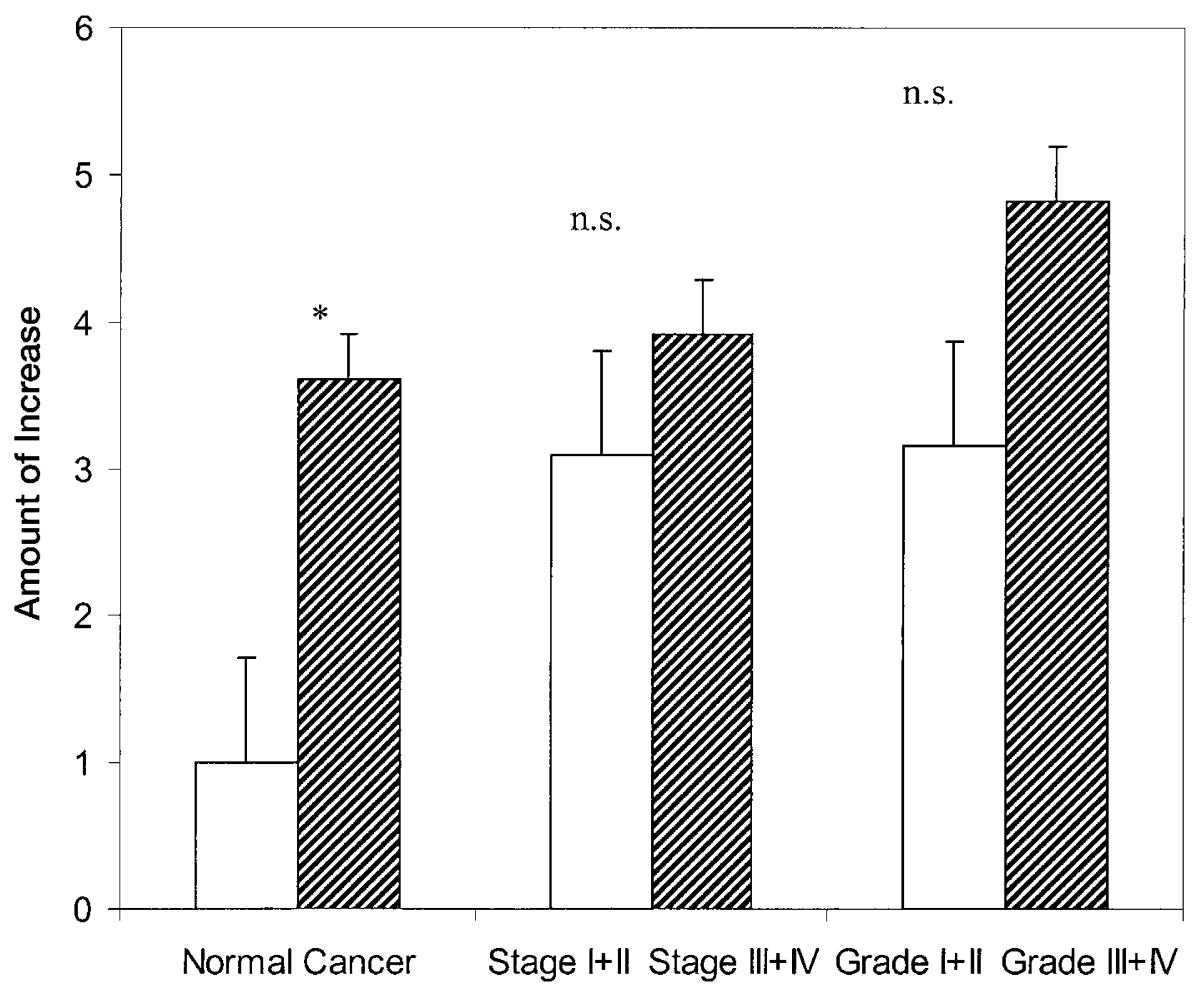

$\begin{array}{lll}\text { A } & \text { B } & \text { C }\end{array}$

\section{Figure 4.}

Comparison of DOC-2 mRNA expression in A, normal and pancreatic cancer samples; B, early versus advanced stages; and C, differentiated versus undifferentiated cancer. The amount of increase over the mean in the normal controls was calculated for each sample. ${ }^{\star} p=0.0006$, n.s. $=$ not significant

were no differences in DOC-2 mRNA expression between early and advanced tumor stages. DOC-2 mRNA and protein were also analyzed in lymph node metastases of pancreatic cancer. In comparison with the corresponding primary tumor, DOC-2 mRNA and protein were markedly reduced and only focally present in some cancer cells. Therefore, downregulation of $D O C-2$ seems to be a late event in the evolution of pancreatic cancer. The mechanisms leading to DOC-2 up-regulation early in the pathogenesis of pancreatic cancer and down-regulation in metastatic disease are not readily apparent. Our cell culture experiments suggest that decreasing $K$-ras mRNA levels in pancreatic cancer cells results in upregulation of DOC-2 mRNA expression, irrespective of whether $K$-ras is mutated or not. These results point to an interesting and novel mechanism of DOC-2 regulation in pancreatic cancer that might, in part, explain the observed down-regulation of DOC-2 in metastatic disease. However, because K-ras mutations occur early in the pathogenesis of pancreatic cancer, other mechanisms must be responsible for the increase in DOC-2 expression in primary cancers.

These results of an increase of DOC-2 expression early in the pathogenesis of pancreatic cancer and a decrease in the late steps of this process (metastasis) are in agreement with previous findings about mucinous ovarian cancer, in which DOC-2 expression generally decreased in Grade 3 tumors, whereas it was expressed in high levels in Grades 1 and 2 tumors (Mok et al, 1998). Supporting this assumption, Northern blot and Western blot analyses revealed very low levels of DOC-2 mRNA and protein in five pancreatic cancer cell lines with a high metastatic potential (Chen et al, 1982; Kyriazis et al, 1982; Lieber et al, 1975; Tan and Chu, 1985; Yunis et al, 1977).

$D O C-2$ is a phosphoprotein with signal transduction capability. The protein kinase C-regulated phosphorylation of DOC-2 may support its growth inhibitory functions (Tseng et al, 1999). As suggested by Fazli and coworkers (1999), DOC-2 probably mediates the signaling of the ovarian surface epithelial cells contacting the extracellular matrix, such as the basement membrane, to ensure the correct location of the mesothelial cells of the surface epithelium. It is therefore possible that loss of DOC-2 in pancreatic cancer cells in primary tumors may also influence their attachment to the basement membrane or extracellular matrix in vivo, thus promoting the metastasis of these cancer cells.

In conclusion, our current findings reveal that $D O C-2$ is overexpressed in pancreatic cancer in comparison with normal pancreatic tissues. Furthermore, enhanced expression of DOC-2 occurs already, early in pancreatic carcinogenesis. Importantly, DOC-2 is markedly reduced in the pancreatic cancer cells of 

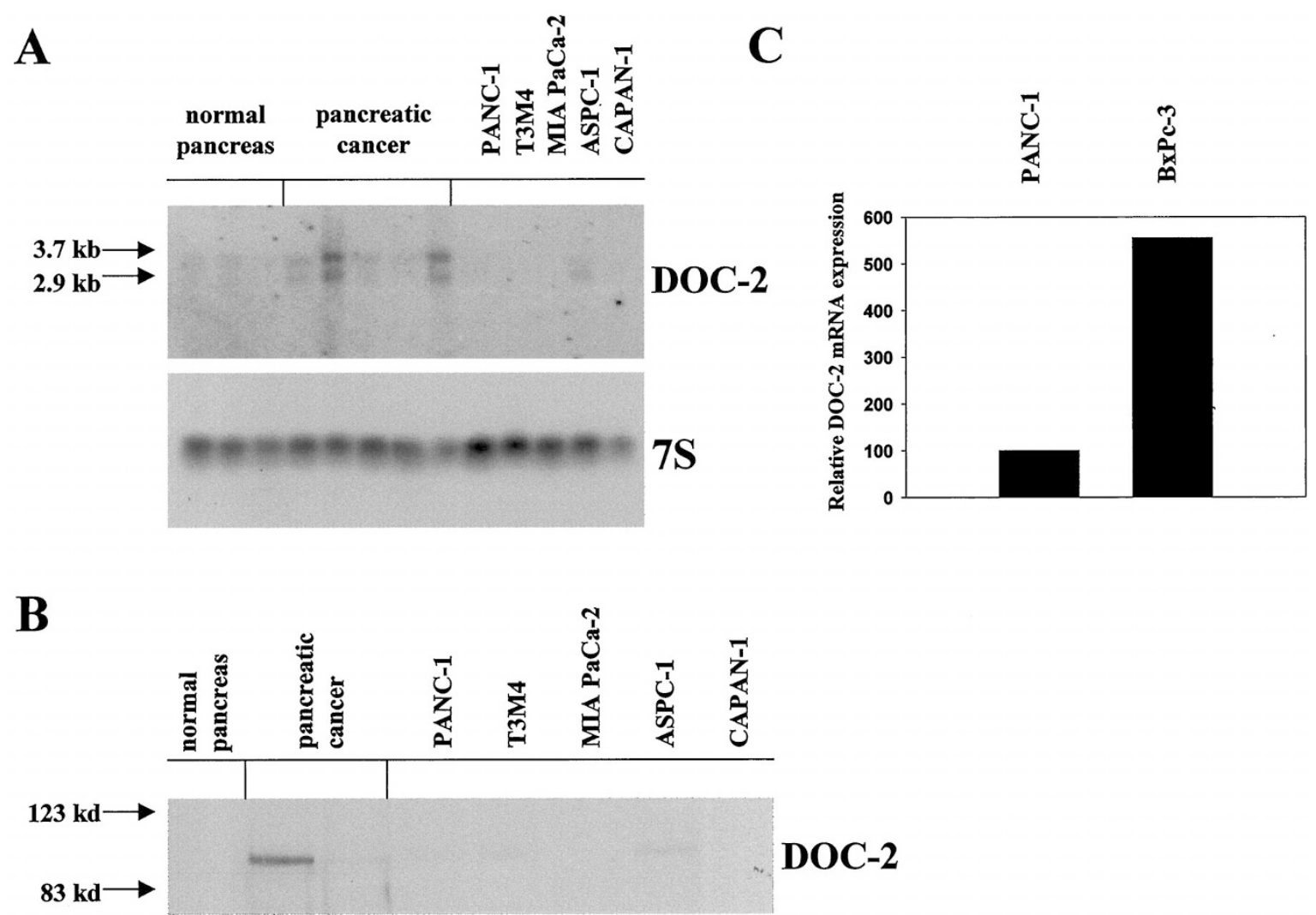

Figure 5.

A, Northern blot analysis of total RNA isolated from the indicated tissues and five pancreatic cancer cell lines. The transcript sizes are indicated on the left side. B, Western blot analysis of $D O C-2$ in five pancreatic cancer cell lines and from the indicated tissues. The size markers are indicated on the left. C, Real-time quantitative RT-PCR of DOC-2 mRNA expression in a metastatic (PANC-1) and a nonmetastatic pancreatic cancer cell line (BxPc-3). Relative DOC-2 mRNA expression compared with PANC-1 cells (100).

lymph node metastases in comparison with their primary tumors. In addition, blocking $K$-ras expression in pancreatic cancer cells leads to an up-regulation of DOC-2 expression. Collectively, our results suggest that the reduced expression of DOC-2 might play a potential role in the formation of metastases during the development of pancreatic cancer.

\section{Materials and Methods}

\section{Patients and Tissue Sampling}

Normal human pancreatic tissue samples were obtained through an organ donor program from 18 individuals ( 11 men, 7 women; median age, 41 years; range, 30-67 years) who were free of any pancreatic disease. Normal ovarian tissue was obtained from three individuals (median age, 57 years) and served as positive control tissue. Primary pancreatic cancer samples and lymph node metastases were obtained from 22 patients (15 men, 7 women; median age, 65.4 years; range, 43-77 years) undergoing pancreatic surgery. According to the tumor node metastasis (TNM) classification of the Union International Contre Cancer (Sobin and Wittekind, 1997), the cancer samples were classified as follows: Stage I (1), Stage II (6), Stage III (13), and Stage IV (2) duct cell adenocarcinomas. Grades 1 and 2 adenocarcinomas $(n=14)$ were summarized as differentiated types. Grades 3 and 4 adenocarcinomas $(n=8)$ were summarized as undifferentiated types.

Tissue samples for immunohistochemistry and in situ hybridization were fixed in 5\% formalin and embedded in paraffin after 24 hours. Immediately after surgical removal, tissue samples destined for RNA extraction were frozen in liquid nitrogen and maintained at $-80^{\circ} \mathrm{C}$ until use. All studies were approved by the Human Subject Committee of the University of Bern.

\section{Cell Culture}

Human pancreatic cancer cells were routinely grown in DMEM (PANC-1, MIA-PaCa-2) or RPMI (T3M4, AsPC-1, Capan-1, BxPc-3) supplemented with 10\% fetal bovine serum, $100 \mathrm{U} / \mathrm{ml}$ of penicillin, and 100 $\mu \mathrm{g} / \mathrm{ml}$ of streptomycin. Cells were maintained at $37^{\circ} \mathrm{C}$ in humidified air with $5 \% \mathrm{CO}_{2}$.

Transfection experiments were carried out as described previously in detail (Kita et al, 1999). Briefly, lipofectamine was gently mixed with the oligonucleotides in a serum-free cell culture medium and incubated at room temperature for 45 minutes to form complexes. Subsequently, the mixtures were added to the subconfluent cells. After 4 hours, an equal volume 
$\mathbf{A}$

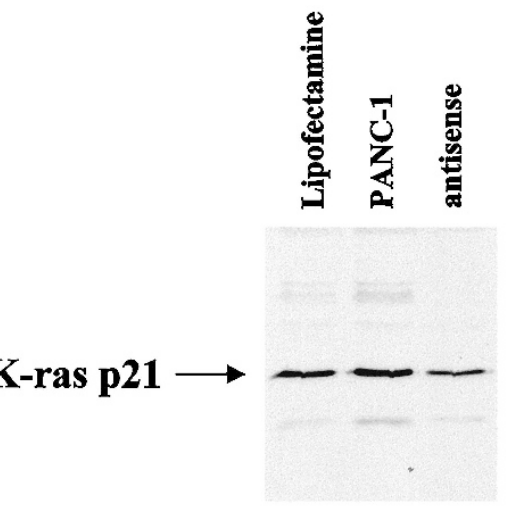

B

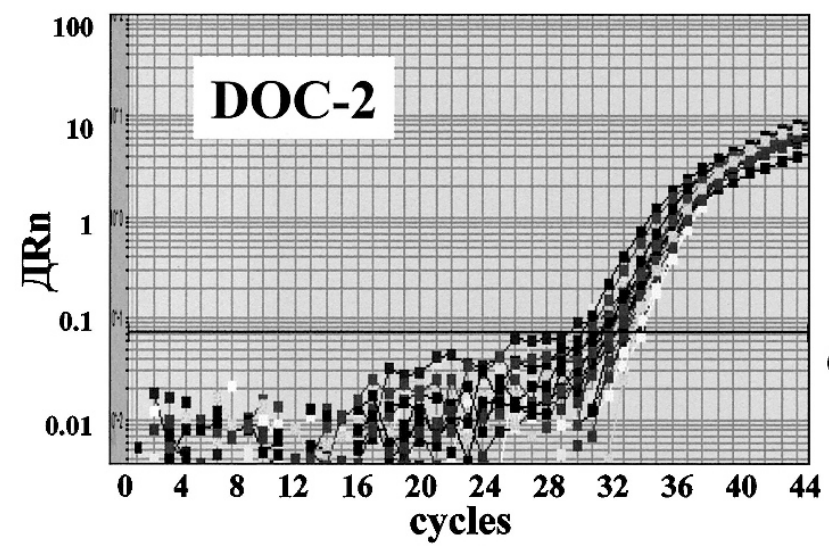

C

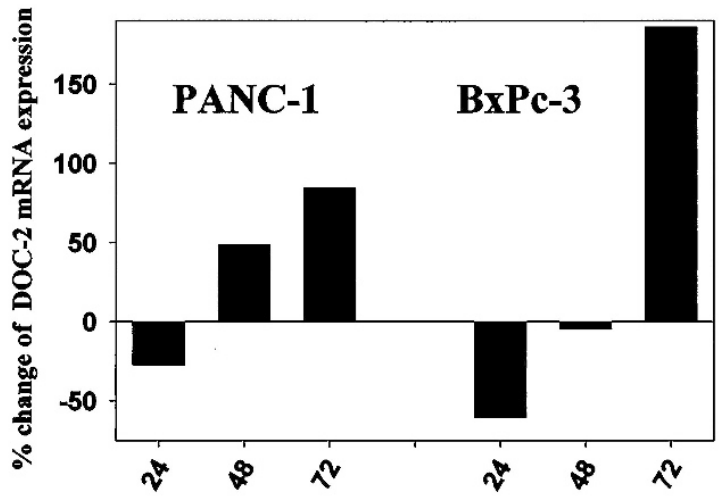

Figure 6.

Effects of $K$-ras down-regulation on DOC-2 mRNA expression levels. A, Western blot analysis demonstrates down-regulation of $K$-ras p21 protein following $K$-ras antisense transfection in PANC-1 cells. B and C, Real time quantitative RT-PCR of DOC-2 (left panel) and $7 S$ (right panel) mRNA expression following K-raS transfection for the indicated time as described in the "Materials and Methods" section (B). For each sample, relative DOC-2 mRNA expression was determined as the ratio of $D O C$-2/7S mRNA expression. To exclude time-dependent effects, DOC-2 mRNA expression following K-ras antisense transfection was normalized to the respective $K$-ras sense transfected controls (C).

of medium containing $20 \%$ fetal bovine serum was added. The final concentrations of lipofectamine and oligonucleotides were $10 \mu \mathrm{g} / \mathrm{ml}$ and $1 \mu \mathrm{M}$, respectively. The design of the specific $K$-ras sense and antisense oligonucleotides has been described previously at length (Kita et al, 1999).

\section{Preparation of Probes}

For Northern blot analysis, a 269-bp fragment (base pairs 464-732, Genbank Access. No. HSU39050) of human DOC-2 cDNA was amplified by RT-PCR using specific primers (forward, 5'-CTTTCATTGCCCGTGATGTG-3'; reverse, 5'-GTCAACACCCGATTCAGTT-3'). The purified PCR products were subcloned into the PGEM-T Easy Vector (Promega Corporation, Madison, Wisconsin), according to the manufacturer's instructions, and the authenticity of the cloned DOC-2 insert was verified by sequencing analysis. Probes for Northern blot analysis were radio-labeled with $\left[\alpha^{-32} \mathrm{P}\right]$ deoxy-cytidine triphosphate, using a random primer labeling system (Pharmacia Biotech AG, Dubendorf, Switzerland). For loading and transfer control, a 190-bp fragment of mouse $7 S$ cDNA that cross hybridizes with human 7S RNA was used as reported previously (Korc et al, 1994).
Sense and antisense probes for in situ hybridization were digoxigenin (DIG) labeled. Antisense probes were made by linearization of the plasmid with $\mathrm{Kspl}$ and transcription using SP6 polymerase and the Ribomax System (Promega Corporation). The transcription resulted in DIG-labeled antisense probes. To evaluate the specificity of the in situ hybridization reaction, a DIG-labeled sense probe was generated after linearization of the plasmid with Pstl and in vitro transcription with T7 polymerase and the Ribomax System.

\section{Northern Blot Analysis}

Total RNA was extracted by the single-step guanidinium isothiocyanate method (Korc et al, 1994), followed by electrophoresis under denaturing conditions in $1.2 \%$ agarose/1.8M formaldehyde gels. The gels were stained with ethidium bromide for verification of RNA integrity and loading equivalency. The RNA was electrotransferred onto nylon membranes (GeneScreen; Du Pont, Boston, Massachusetts) and crosslinked by ultraviolet irradiation. The blots were then prehybridized for 4 hours at $42^{\circ} \mathrm{C}$, in $50 \%$ formamide, $1 \%$ SDS, $5 \times$ Denhardt's solution, $250 \mu \mathrm{g} / \mathrm{ml}$ salmon 
sperm DNA, 50 mm Na2PO4 (pH 7.4), 10\% dextran, 75 $\mathrm{mm} \mathrm{NaCl}$, and $5 \mathrm{~mm}$ EDTA. The blots were then hybridized for 16 hours at $42^{\circ} \mathrm{C}$ in the presence of the $\alpha{ }^{32}$ PCTP-labeled DOC-2 cDNA probe $\left(10^{6} \mathrm{cpm} / \mathrm{ml}\right)$, rinsed twice with $2 \times \mathrm{SSC}$ at $55^{\circ} \mathrm{C}$, and washed twice with $0.2 \times \mathrm{SSC} / 2 \% \mathrm{SDS}$ at $55^{\circ} \mathrm{C}$ for 10 minutes each. Blots were exposed at $-80^{\circ} \mathrm{C}$ to Fuji $\mathrm{x}$-ray films with Kodak intensifying screens for 1 to 10 days. The intensity of the radiographic bands was quantified by video densitometry.

\section{In Situ Hybridization}

In situ hybridization was performed as previously reported (Lu et al, 1997). Consecutive slides were incubated with the sense probes and antisense probes. The tissue sections $(4 \mu \mathrm{m})$ were deparaffinized, dehydrated, and incubated in $0.2 \mathrm{M}$ of $\mathrm{HCl}$ and proteinase $\mathrm{K}\left(50 \mu \mathrm{g} / \mathrm{ml}\right.$ for 20 minutes at $\left.37^{\circ} \mathrm{C}\right)$. After postfixation with $4 \%$ paraformaldehyde in PBS for 5 minutes, the samples were prehybridized at $56^{\circ} \mathrm{C}$ for at least 1 hour in $50 \%$ formamide (v/v), $4 \times$ SSC, $2 \times$ Denhardt's solution, $500 \mu \mathrm{g} \mathrm{RNA} / \mathrm{ml}$, and $10 \%$ dextran sulfate $(\mathrm{w} / \mathrm{v})$. The final concentrations of the DIG-labeled probes were approximately $0.25 \mathrm{ng} / \mu \mathrm{l}$. After hybridization, excess probe was removed by washing in $2 \times$ SSC and RNase treatment. Washings were performed at $62^{\circ} \mathrm{C}$ in $2 \times \mathrm{SSC}$ for 10 minutes twice and in $0.2 \times \mathrm{SSC} / 30 \%$ formamide for 10 minutes twice. Afterward, the sections were incubated with an anti-DIG antibody conjugated with alkaline phosphatase and nitroblue tetrazolium. For control experiments, the slides were incubated with RNase or with the corresponding sense probes. Pretreatment of the slides with RNase abolished the hybridization signals produced by the antisense probe. Furthermore, incubation with the sense probe failed to produce specific in situ hybridization signals.

\section{Immunohistochemistry}

Immunohistochemical analysis was performed with the streptavidin-peroxidase technique as previously reported (Graber et al, 1995). Antiserum ( $\alpha \mathrm{M} 2)$ raised against a synthetic peptide (IDEKTGVI EHEH PVNKIS) was used as a primary antibody (polyclonal rabbit anti-DOC-2 antibody, dilution of 1:1000). The specificity of the anti-DOC-2 antibody was described previously in detail (Fulop et al, 1998; Mok et al, 1998). Briefly, consecutive 4- $\mu \mathrm{m}$ paraffin-embedded tissue sections were deparaffinized and dehydrated. Endogenous peroxidase activity was blocked by incubating the slides in methanol containing $0.6 \%$ hydrogen peroxide, followed by washing with tris-buffered saline/0.1\% BSA. The sections were then incubated for 30 minutes at room temperature with $10 \%$ normal goat serum, before overnight incubation at $4^{\circ} \mathrm{C}$ with the primary antibody. Next, the sections were incubated with a biotinylated goat anti-rabbit IgG (secondary antibody) and streptavidin peroxidase complex, followed by reaction with $0.05 \%$ diaminobenzidine and counterstaining with Mayer's hematoxylin. To ensure the specificity of the primary antibody, tissue sections were incubated in the absence of the primary antibody or with preimmunized rabbit serum. In these cases, no immunostaining was detected. Results were evaluated by two independent observers.

\section{Western Blot Analysis}

Homogenates of five normal pancreatic samples, eight pancreatic cancer samples, and cell lysates from cultured pancreatic cancer cell lines (PANC-1, T3M4, MIA PaCa-2, AsPC-1, Capan-1) were subjected to $7.5 \%$ SDS-PAGE for DOC-2 immunoblotting.

After electrophoresis of $30 \mu \mathrm{g}$ of protein and transfer to nitrocellulose membranes, the membranes were blocked for 1 hour with $5 \%$ nonfat dry milk and incubated for 2 hours with an anti-DOC-2 monoclonal antibody (1:2500 dilution) generated against a synthetic peptide (GSEKTDEYLLARFKG; Transduction Laboratories, Lexington, Kentucky) (Albertsen et al, 1996; Bork and Margolis, 1995). The specificity of this antibody was also described before in detail (Mok et al, 1998). For detection of $K$-ras p21 protein expression, membranes were probed with a specific p21 monoclonal antibody (Oncogene Science, Cambridge, Massachusetts) as described previously (Kita et al, 1999). After washing, filters were incubated with a 1:5000 dilution of the secondary antibody for 60 minutes, and the signals were visualized by an enhanced chemiluminescence technique.

\section{Real-Time Quantitative RT-PCR}

Total RNA was isolated as described. After DNase treatment, total RNA was reverse transcribed into cDNA using random hexamers according to the manufacturer's instructions (Roche Diagnostics, Rotkreuz, Switzerland). The real-time quantitative RT-PCR analysis was performed with an automated sequence detection system (Prism 7700 Sequence Detector; PE Applied Biosystems, Weiterstadt, Germany), combined with a dual-label fluorogenic detection system (TaqMan, PE Applied Biosystems) based upon the $5^{\prime}$ nuclease assay. The human $7 S$ rRNA gene was used as an endogenous control. For the PCR reaction, the primers and the probes for DOC-2 and human $7 S$ were designed using primer design software (Primer Express, PE Applied Biosystems) and synthesized by PE Applied Biosystems. The following primers were used: DOC-2, forward primer 5'-AAT GAG CCA AGA CTC TAT GAT GAA ACT A-3'; reverse primer 5'-CTA TTA CCC CAG TTT TCT CAT CAA TTA ТT-3'; probe 5'-FAM-TGG TCG GTC TCA GGG ACA ACA CAA ACA-3'TAMRA; 7S, forward primer 5'-ACC ACC AGG TTG CCT AAG GA-3'; reverse primer 5'-CAC GGG AGT TIT GAC CTG CT-3'; probe 5'FAM-TGA ACC GGC CCA GGT CGG AAA-3'TAMRA. All amplification reactions were carried out in a final volume of $25 \mu \mathrm{l}$ containing $12.5 \mu \mathrm{l}$ of the TaqMan PCR Core Reagent kit (PE Applied Biosystems) and $11 \mathrm{ng}$ of cDNA. Concentrations of primers and probes were optimized as follows: $300 \mathrm{~nm}$ for DOC-2 forward primer and 
reverse primer, $200 \mathrm{nM}$ for DOC-2 probe (FAM/ TAMRA), and $300 \mathrm{~nm}$ for 75 forward primer, $7 S$ reverse primer, and $7 S$ probe (FAM/TAMRA). Thermal cycling was initiated with a 2 -minute incubation at $50^{\circ} \mathrm{C}$ for uracil $\mathrm{N}$-glycosylase reaction, followed by a 10-minute reaction at $95^{\circ} \mathrm{C}$ to activate the AmpliTaq Gold (PE Applied Biosystems), and 45 PCR cycles for DOC-2 and $7 S$ at $95^{\circ} \mathrm{C}$ for 15 seconds and $60^{\circ} \mathrm{C}$ for 1 minute. Each PCR run included five standards, one template control, and certain experimental sample points. Standard curves for both DOC-2 and $7 S$ were generated using a cDNA synthesized from serial 1:5 dilution of total RNA of one pancreatic cancer sample. The threshold was set at 10 standard deviations above the mean of the baseline fluorescence emission, calculated from cycles 3 to 19 (for DOC-2) and 3 to 18 (for $7 S)$. The point at which the amplification plot crosses this threshold was defined as $\mathrm{Ct}$, which represents the cycle number at this point. The relative standard curve was constructed by seven standard $\mathrm{Ct}$ values, as $y$-axis values, and the log of the input standard RNA amount (copy number). For each experimental sample, the amounts of DOC-2 mRNA and 7S mRNA were determined from the standard curve. The normalized amount of DOC-2 was determined by dividing the amount of DOC-2 mRNA by the amount of 75 mRNA for each sample.

\section{Statistical Analysis}

Data are expressed as median and range. For statistical analysis the Mann-Whitney $U$ test was used. A value of $p<0.05$ was taken as significant.

\section{References}

Albertsen HM, Smith SA, Melis R, Williams B, Holik P, Stevens J, and White R (1996). Genomic structure, and chromosomal assignment of human DOC-2. Genomics 33: 207-213.

Bork P and Margolis B (1995). A phosphotyrosine interaction domain. Cell 80:693-694.

Bos JL (1989). ras oncogenes in human cancer: A review. Cancer Res 49:4682-4689.

Chen WH, Horoszewicz JS, Leong SS, Shimano T, Penetrante R, Sanders WH, Berjian R, Douglass HO, Martin EW, and Chu TM (1982). Human pancreatic adenocarcinoma: In vitro and in vivo morphology of a new tumor line established from ascites. In Vitro 18:24-34.

Fazili Z, Sun W, Mittelstaedt S, Cohen C, and Xu XX (1999). Disabled-2 inactivation is an early step in ovarian tumorigenicity. Oncogene 18:3104-3113.

Friess H, Guo XZ, Berberat P, Graber HU, Zimmermann A, Korc M, and Büchler MW (1998). Reduced KAl1 expression in pancreatic cancer is associated with lymph node and distant metastases. Int J Cancer 79:349-355.

Friess H, Yamanaka Y, Büchler M, Ebert M, Beger HG, Gold LI, and Korc M (1993). Enhanced expression of transforming growth factor beta isoforms in pancreatic cancer correlates with decreased survival. Gastroenterology 105:1846-1856.
Fulop V, Colitti CV, Genest D, Berkowitz RS, Yiu GK, Ng SW, Szepesi J, and Mok SC (1998). DOC-2/hDab2, a candidate tumor suppressor gene involved in the development of gestational trophoblastic diseases. Oncogene 17:419-424.

Graber H, Müller CF, Vandevelde M, and Zurbriggen A (1995). Restricted infection with canine distemper virus leads to down-regulation of myelin gene transcription in cultured oligodendrocytes. Acta Neuropathol 90:312-318.

Gudjonsson B (1995). Carcinoma of the pancreas: Critical analysis of costs, results of resections, and the need for standardized reporting. J Am Coll Surg 181:483-503.

Kavanaugh WM and Williams LT (1994). An alternative to SH2 domains for binding tyrosine-phosphorylated proteins. Science 266:1862-1865.

Kita K, Saito S, Morioka CY, and Watanabe A (1999). Growth inhibition of human pancreatic cancer cell lines by anti-sense oligonucleotides specific to mutated k-ras genes. Int J Cancer 80:553-558.

Korc M, Chandrasekar B, Yamanaka Y, Friess H, Büchler M, and Beger HG (1992). Over-expression of the epidermal growth factor receptor in human pancreatic cancer is associated with concomitant increases in the levels of epidermal growth factor and transforming growth factor alpha. J Clin Invest 90:1352-1360.

Korc M, Friess H, Yamanaka Y, Kobrin MS, Büchler M, and Beger HG (1994). Chronic pancreatitis is associated with increased concentrations of epidermal growth factor receptor, transforming growth factor alpha, and phospholipase C gamma. Gut 35:1468-1473.

Kyriazis AP, Kyriazis AA, Scarpelli DG, Fogh J, Rao MS, and Lepera R (1982). Human pancreatic adenocarcinoma line Capan-1 in tissue culture and the nude mouse: Morphologic, biologic, and biochemical characteristics. Am J Pathol 106: $250-260$.

Liang P and Pardee AB (1992). Differential display of eukaryotic messenger RNA by means of the polymerase chain reaction. Science 257:967-971.

Lieber M, Mazzetta J, Nelson-Rees W, Kaplan M, and Todaro G (1975). Establishment of a continuous tumor-cell line (panc-1) from a human carcinoma of the exocrine pancreas. Int J Cancer 15:741-747.

Lu Z, Friess H, Graber HU, Guo X, Schilling M, Zimmermann A, Korc M, and Büchler MW (1997). Presence of two signaling TGF-beta receptors in human pancreatic cancer correlates with advanced tumor stage. Dig Dis Sci 42:2054-2063.

Mangray S and King TC (1998). Molecular pathobiology of pancreatic adenocarcinoma (Review). Front Biosci 3:D11481160.

Mok SC, Bell DA, Knapp RC, Fishbaugh PM, Welch WR, Muto MG, Berkowitz RS, and Tsao SW (1993). Mutation of K-ras protooncogene in human ovarian epithelial tumors of borderline malignancy. Cancer Res 53:1489-1492.

Mok SC, Chan WY, Wong KK, Cheung KK, Lau CC, Ng SW, Baldini A, Colitti CV, Rock CO, and Berkowitz RS (1998). DOC-2, a candidate tumor suppressor gene in human epithelial ovarian cancer. Oncogene 16:2381-2387.

Mok SC, Wong KK, Chan RK, Lau CC, Tsao SW, Knapp RC, and Berkowitz RS (1994). Molecular cloning of differentially expressed genes in human epithelial ovarian cancer. Gynecol Oncol 52:247-252. 
Ren R, Mayer BJ, Cicchetti P, and Baltimore D (1993). Identification of a ten-amino acid proline-rich $\mathrm{SH} 3$ binding site. Science 259:1157-1161.

Rivera JA, Rall CJ, Graeme-Cook F, Fernandez-del Castillo C, Shu P, Lakey N, Tepper R, Rattner DW, Warshaw AL, and Rustgi AK (1997). Analysis of K-ras oncogene mutations in chronic pancreatitis with ductal hyperplasia. Surgery 121:4249.

Sobin LH and Wittekind C (1997). Pancreas. In: Sobin LH and Wittekind $\mathrm{CH}$, editors. TNM classification of malignant tumors, 5th ed. International Union Against Cancer (UICC). New York: Wiley-Liss, Inc., 87-90.

Tan MH and Chu TM (1985). Characterization of the tumorigenic and metastatic properties of a human pancreatic tumor cell line (AsPC-1) implanted orthotopically into nude mice. Tumor Biol 6:89-98.
Tseng CP, Ely BD, Pong RC, Wang Z, Zhou J, and Hsieh JT (1999). The role of DOC-2/DAB2 protein phosphorylation in the inhibition of AP-1 activity. An underlying mechanism of its tumor-suppressive function in prostate cancer. J Biol Chem 274:31981-31986.

Xu XX, Yang W, Jackowski S, and Rock CO (1995). Cloning of a novel phosphoprotein regulated by colony-stimulating factor 1 shares a domain with the Drosophila disabled gene product. J Biol Chem 270:14184-14191.

Xu XX, Yi T, Tang B, and Lambeth JD (1998). Disabled-2 (Dab2) is an SH3 domain-binding partner of Grb2. Oncogene 16:1561-1569.

Yunis AA, Arimura GK, and Russin DJ (1977). Human pancreatic carcinoma (MIA PaCa-2) in continuous culture: Sensitivity to asparaginase. Int J Cancer 19:218-235. 